\title{
Article
}

\section{From Data to Wisdom: A Case Study of OPOP Model}

\author{
Yikang Sun ${ }^{1}\left(\mathbb{D}\right.$, Po-Hsien $\operatorname{Lin}^{2}$ and Rungtai Lin ${ }^{2, *} \mathbb{C}$ \\ 1 College of Art \& Design, Nanjing Forestry University, Nanjing 210037, China; sunyikang120110@hotmail.com \\ 2 Graduate School of Creative Industry Design, National Taiwan University of Arts, \\ New Taipei City 22058, Taiwan; t0131@mail.ntua.edu.tw \\ * Correspondence: rtlin@mail.ntua.edu.tw
}

check for updates

Citation: Sun, Y.; Lin, P.-H.; Lin, R. From Data to Wisdom: A Case Study of OPOP Model. Educ. Sci. 2021, 11, 606. https://doi.org/10.3390/ educsci11100606

Academic Editor: Mike Joy

Received: 1 August 2021

Accepted: 28 September 2021

Published: 1 October 2021

Publisher's Note: MDPI stays neutral with regard to jurisdictional claims in published maps and institutional affiliations.

Copyright: (c) 2021 by the authors. Licensee MDPI, Basel, Switzerland. This article is an open access article distributed under the terms and conditions of the Creative Commons Attribution (CC BY) license (https:// creativecommons.org/licenses/by/ $4.0 /)$.

\begin{abstract}
The purpose of this research is to: (1) clarify the scope and connotation of the OPOP (One Product/Project/Performance, One Paper) model comprehensively; (2) show its application in design and creative teaching; (3) introduce this model to more people. First, the author reviews the design doctoral education system and its shortcomings and analyzes the similarities and differences between "Ph.D. of Design" and "Master of Design"; second, the researcher discusses the DIKW (Data, Information, Knowledge, Wisdom) pyramid, cognition and communication theory separately. The author also interviewed the two teachers who created the OPOP model to clarify its core meaning and goals. Finally, the author invited students who participated in an OPOP forum to fill out a questionnaire in order to analyze and understand their responses and suggestions. The OPOP model allows participants to realize that "creativity" and "interpretation" are equally important and to gradually learn to use academic papers to transform personal "tips" and "experience" into "knowledge" that can be imparted. The author hopes that the OPOP model and the general frameworks mentioned in this study can inspire all readers, enabling them to continuously explore the connotation and further possibilities of OPOP in light of the actual situation.
\end{abstract}

Keywords: OPOP model; DIKW pyramid; creativity and interpretation; cognition and communication; design education; interdisciplinary

\section{Introduction}

Design is a highly applied subject. Generally speaking, when a design is recognized by the market and consumers, it can gain profits for the company and gain prestige for the brand. For designers and manufacturers, in addition to ensuring the quality of the design and the appropriate price, how the interpretation of the design works for others is also very important. Even if a design is excellent, if its designer cannot effectively transmit the connotation of his work, it may not easily attract a consumer's attention.

Although the fields, goals, and potential audiences of different types of designs are different, they usually need to meet the criteria called "Good Design". At the same time, these designs also need to be as close as possible to their desired essence and goals [1-8]. However, consumers may not understand these slightly wordy guidelines which also require designers to use simpler, straightforward, and simple design language to pass on their design concepts and characteristics to others. Even if a product is functionally inadequate, if the people who see it can feel the story behind the design, a certain consensus can be formed between the designer and the user. It is likely to make this product more popular, because attractive things will make people feel better. The Juicy Salif, designed by Philip Stark, is perhaps one of the more successful cases of "interpretation" design [9]. As Starck stated: "My juicer is not meant to squeeze lemons; it is meant to start conversations [10]".

Therefore, for designers, in addition to mastering the basic skills and literacy of designing, they must also learn how to successfully sell their own designs; that is, how to pass their ideas clearly to others. It is hoped that, through the OPOP teaching model, students can develop research-based logical thinking and have the ability to effectively 
convey the intention and connotation of their works. At the same time, the education and training of design patterns can also introduce the OPOP model because the doctoral education in the field of design focuses more on the training of logical thinking, and the ability to dig deeper and explore the essence of design.

The course of this study is as follows: first, the author reviews the design doctoral education system and its shortcomings and analyzes the similarities and differences between "Ph.D. of Design" and "Master of Design"; secondly, the researcher discusses the DIKW (Data, Information, Knowledge, and Wisdom) pyramid, cognition and communication theory separately. In order to clarify the core meaning and goals of the OPOP model, the author also presents the results of interviews with the two teachers who created it. Finally, the author invited students who participated in an OPOP forum to fill out a questionnaire in order to analyze and understand their responses and suggestions. The OPOP model allows participants to realize that "creativity" and "interpretation" are equally important and to gradually learn to use academic papers to transform personal "tips" and "experience" into "knowledge" that can be imparted. The purpose of this research is to: (1) clarify the scope and connotation of the OPOP model comprehensively; (2) show its application in design and creative teaching; (3) introduce this model to more people. The author hopes that the OPOP model and the general frameworks discussed in this study can inspire all readers, enabling them to continuously explore the connotation and more possibilities of OPOP in light of the actual situation.

\section{Background}

\subsection{The Intention and Shortcoming the Doctoral Education of Design}

When the social and economic level of a country or region has developed to a certain level, design education comes into being. Since the 20th century, the German model has always occupied a pivotal position in the global design field, forming the Bauhaus-Ulm System [11-16]. The German design education model has become the benchmark in many countries. Even though national conditions and cultures are different, the core part of the design education models, concepts, and theories in many countries and regions can be seen in the shadow of the "Bauhaus-Ulm System". In addition, some countries and regions in East Asia have also been affected by the Bauhaus trend, and their design education models generally follow the above-mentioned system [17-25].

Since the 20th century, with the advancement of technology, the history of design development can be roughly divided into five stages. Each stage can be described by an "F": (1) Design for Function in the 1930s; (2) Design for Friendly in the 1950s; (3) Design for Fun in the 1970s; (4) Design for Fancy in the 1990s; (5) Design for Feeling since the 21st century [26-28]. The core concept of modern design can be summarized into four main characteristics, namely: (1) "serving the most people" (the ultimate goal), (2) "Form follows Function" (core theory), (3) "Form follows Market" (realistic considerations) and (4) "Form follows Life" (deep experience). The model and content of design education have been continuously adjusted and expanded along with the development process which was mentioned (see Figure 1), and its importance is increasing day by day [29-35].

We believe that researchers need to understand the development pulse and laws of modern design, and need to firmly grasp the current and future design hot topics, which will help us construct a more suitable design education model.

For designers, they not only need to design a product that can solve practical problems and is easy to use, but also require the product (or service) to bring users a sense of pleasure and even a deeper experience. Most of the countries or regions where design development is relatively mature have experienced the development process from OEM (Original Equipment Manufacturer) to ODM (Original Design Manufacturer) and, then, to OBM (Own Branding and Manufacturing). In this regard, Lin, Kreifeldt, and Huang and Chen [36] centered on the trend of design development in Taiwan and put forward three trends of current and future design development: (1) From Function to Feeling; (2) From Use to User; (3) From High-tech to High-touch. That is, design has gone from "solving 
problem" to the level of increasing taste and pleasure. Therefore, this requires designers to continuously improve their abilities, not only to master the skills of "making design", but also to have the concept of "interpreting". This also requires that the model of design education be constantly adjusted.

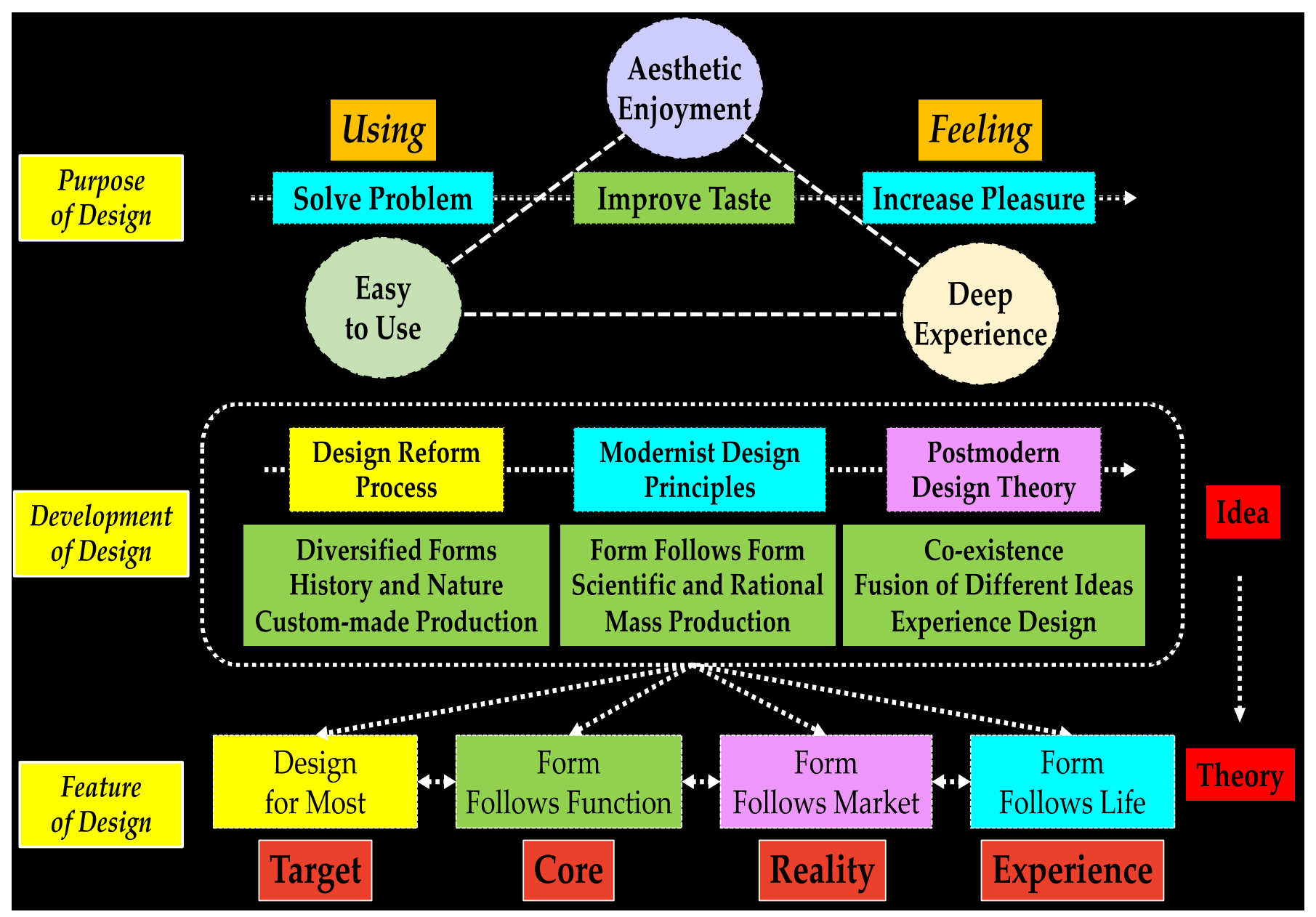

Figure 1. Thinking about the design education model from the perspective of the development process of modern design and its core concepts. (Source: this study.)

We are accustomed to using "Master of Design" to refer to designers who are achieving outstanding achievements. These masters focus on creation, and they also write books to explain and promote their design concepts. At the same time, there is also a group of scholars in universities or research institutions, among whom most have obtained or are about to obtain doctoral degrees, and who have developed critical thinking under systematic and professional training.

In the academic education of the arts major, the Master of Fine Arts (MFA) is the highest degree that students engaged in artistic creation can obtain. In recent years, many schools have begun to grant qualified students a Doctor of Fine Arts (DFA) or a Doctor of Philosophy degrees in the traditional sense. However, what is the purpose of doctoral education in design disciplines? Do people who are engaged in design practice have to take a Ph.D.? "Master of Design" and "Ph.D. of Design" are not comparable. If we must point out the difference between the two, the author believes that the former focuses on sharing with others their own tips and experiences, while the latter can transform them into knowledge, and then rise to a deeper level of wisdom. 


\subsection{The Development and Current Situation of Design Education in Taiwan}

The Bauhaus movement has been the greatest influence on the design field in the 20th century. In general, the development of Taiwan's design education was followed the concept of the Bauhaus style. Prof. Lin, from one of the research teams, has conducted many researches on design education in Taiwan, and published them in journals and academic seminars [36-39]. Based on the above reasons, this section does not spend too much space to discuss design education in Taiwan, and the OPOP model is also proposed by Prof. Po-Hsien Lin and Prof. Rungtai Lin based on his thoughts on design education in Taiwan and the world.

From the perspective of Taiwan's design education system, many high schools and vocational schools have design-related departments. From the perspective of their curriculum settings, they are not much different from the first and second grades of university design departments. After 2 to 3 years of academic and technical training, these high school or vocational school students have all the skills needed to engage in design practice. In terms of actual experience and skills, they may be richer and more proficient than college students and graduate students. The author believes that studying in a university or graduate school should be more about the training and development of a thinking model, improving understanding from the "concept" level, and developing a mode of critical thinking.

The formulation of a major or subject teaching model is often through to consist of multiple demonstrations and experiments, with the principle that most students can adapt. Although some courses are taught in small classes, they still cannot be tailored specifically for each student. In other words, some of the course content and teaching methods may make some students uncomfortable. Even the courses of a graduate school may not all adopt the "one-to-one" teaching model. Therefore, in addition to the educator who can continuously improve and revise the content of the curriculum and the classroom model, students also need to know the crux of their own "unsuitability".

In summary, the teaching mode of design creativity needs to be continuously adjusted according to the development of design, and it also needs to better guide students. Teachers not only teach students basic skills, but more importantly, they also need to inspire students' ideas and concepts, and enable students to master effective methods, such as how to effectively interpret their designs and creativity. Especially in recent years, artificial intelligence has been involved in design creation [40]. Perhaps designers will not be unemployed in the short-term, but from the perspective of development trends, we need to master the ability to "interpret" design. Otherwise, it is easy to be eliminated by the times.

\section{The Theoretical Framework and Methods}

\subsection{The DIKW Pyramid}

Students and designers in the design field are often more willing to write design reports rather than articles. The reasons for this vary from person to person. The author believes that, apart from not mastering effective research methods, they may not be able to clarify the relationship between creation, design, and research. Knowledge is the tips and experience of the ancestors; it is the result of a systematic analysis, sorting, and research. It can be stated: "The value of tips is sharing, the value of experience is inheritance, and the value of knowledge is transmitting". Therefore, the value of research is to share the tips and turn them into experience which can be passed on and turned into knowledge which can then be imparted through analysis and induction.

Many professors work in the emerging research field of how to turn the creative process into knowledge that can be imparted. In the process of creation and design, we have accumulated a wealth of experience and knowledge. Why cannot they be transformed into knowledge that can be imparted through systematic research? Creation refers to the process of "coding" and "decoding" observation and experience of daily life which creators express in a new form. For creators, the theme of creation and the motivation behind it may be simple or complex. It is one of the means for creators to express their personal feelings and characteristics. 
Research produces knowledge and knowledge is a tool that uses known theories to explain various phenomena in daily life. Research is the analysis of phenomena that cannot be explained by knowledge in daily life, and after theoretical verification, it becomes knowledge that can be learned. The purpose of the research is to find ways to find practical and feasible methods for problems that cannot be solved with existing knowledge, and to turn them into theoretical bases that can be copied or reused. The Massachusetts Institute of Technology (MIT) divides the ultimate goal of knowledge education into three levelsReason, Knowledge, and Wisdom-, and fully expresses them in the curriculum [41]. On the other hand, "research, teaching, and service" is the teacher's duty, because research can generate knowledge, and the purpose of teaching is to spread knowledge. Finally, applying knowledge in practice can be called a service. The purpose of our research is to turn the original data into useful information through an analysis and synthesis; then, to analyze and summarize this information into useful knowledge. Finally, through teaching, the knowledge can be passed on and applied flexibly in daily life. The relationship between the teacher's duty (Research, Teaching, and Service) and the three levels of education goals (Reason, Knowledge, and Wisdom) are shown in Figure 2.

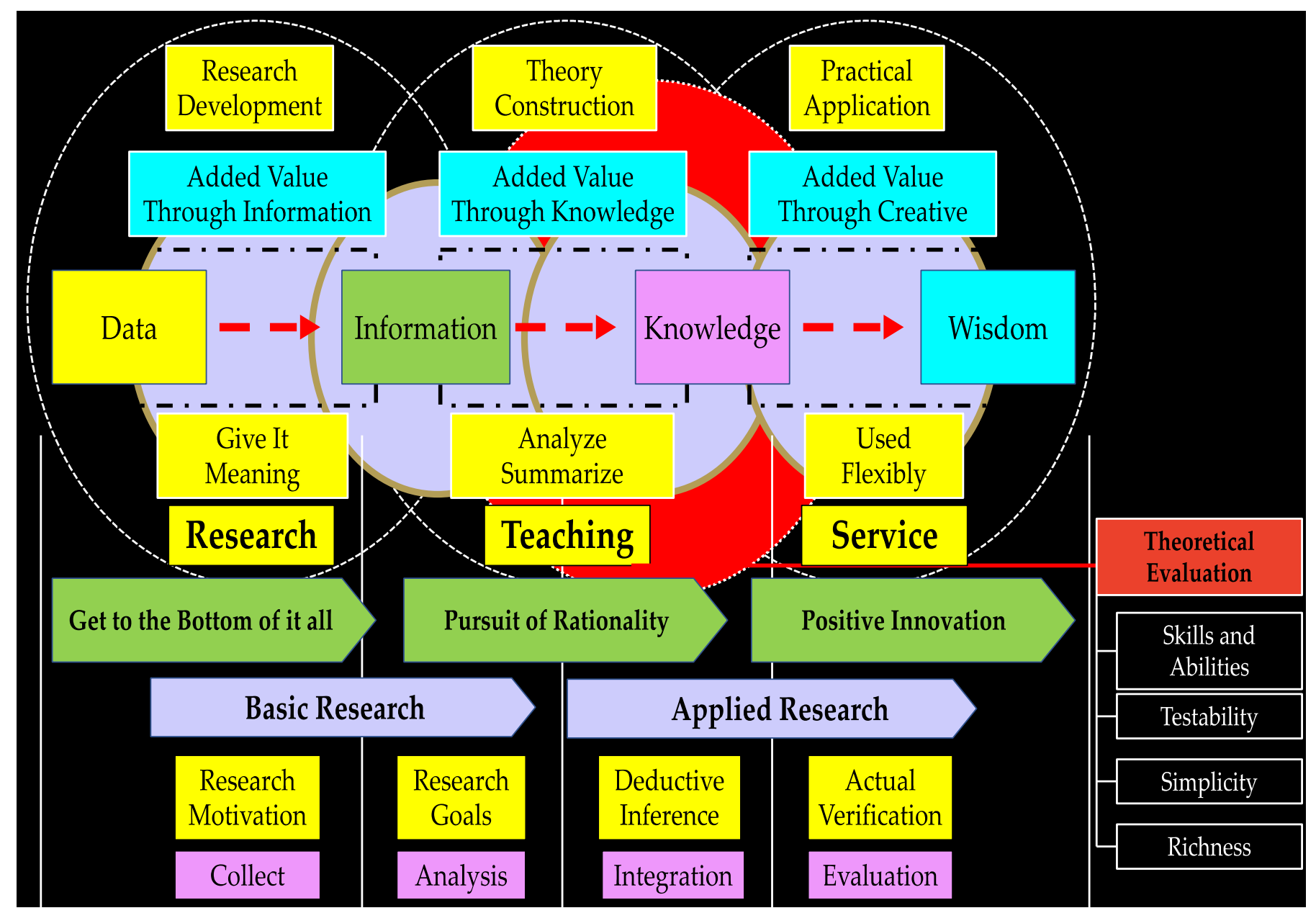

Figure 2. Research framework from Data to Wisdom. (Reprinted with permission from [42]. Copyright 2009 Lin, R. et al.)

\subsection{Design Research: From Individual to General}

The difference between creation and design may be considered from the purpose of creation. Different from applied art, the creation mentioned here focuses more on the level of appreciation and feeling. At this time, the motivation of creation may be very personal, and the so-called motivation may not even exist. It may just be a whim of the creator. Creators are often unwilling to follow the trend and be similar to others. Coupled with 
many creative works, it may be just for appreciation. At this time, the creator does not have to consider various specific situations such as creating design. This may also be a certain characteristic contained in the broad sense of creation. Therefore, writing a creation into a paper is not only a case study, but also a sharing of tips and experience, and a process of "From Data to Wisdom" [43-45].

The question is, what kind of case studies can be written as articles and accepted and published by prestigious domestic and foreign journals? Articles are a kind of "Quasiknowledge". Therefore, an excellent case study needs to be carried out using the DIKW system. Design is also a form of creation. In terms of modern design, it is a combination of sensibility (humanities and arts) and rationality (science and technology). It requires not only the spirituality and sensibility of artistic creation, but also the rigor and rationality of engineering and science when facing problems. For researchers, in order to explore whether there is a certain rule in creation, it is necessary to choose appropriate research methods to carry out corresponding research. As a result, it is possible to find a certain rule (abstract) or a certain pattern (concrete). The quality of creation should be an abstract, reproducible or reusable theoretical basis. If researchers can find out such internal laws, they are naturally happy. Tables 1 and 2 show the similarities and differences between different studies (such as articles, reports).

Table 1. The similarities and differences between academic articles, design creation reports, and creation reports.

\begin{tabular}{lll}
\hline \multicolumn{1}{c}{ Academic Articles } & \multicolumn{1}{c}{ Design Creation Reports } & \multicolumn{1}{c}{ Creation Reports } \\
\hline 1. Literature Review & 1. Design Theory Discussion & 1. Theoretical Foundation \\
2. Theory Construction & 2. Design Concept Construction & 2. Creative idea \\
3. Research Design & 3. Exploration of the Way of Design and Design Method & 3. Methods and Techniques \\
4. Results and Analysis & 4. Design Results and Analysis & 4. Content and Form \\
5. Discussion & 5. Discussion Between Results, Ideas and Theories & 5. Artistic Value and Contribution \\
6. Conclusions and Suggestions & 6. Conclusions and Suggestions & \\
\hline
\end{tabular}

(Source: this study.)

Table 2. The similarities and differences between creation reports, creation papers, and academic articles.

\begin{tabular}{lllll}
\hline \multicolumn{1}{c}{ Creation Reports } & \multicolumn{1}{c}{ Create Papers } & \multicolumn{1}{c}{ Create Papers } & \multicolumn{1}{c}{ Create Papers } & \multicolumn{1}{c}{ Academic Articles } \\
\hline & & 1. Theoretical Foundation & 1. Theoretical Foundation & 1. Theoretical Foundation \\
1. Theoretical Foundation & 1. Theoretical Foundation & 2. Pre-study & 3. Conclusions & 2. Literature Review \\
2. Design Practice & 2. Design Practice & 3. Conclusions & 3. Research Framework \\
3. Creative Review & 3. Creative Review & 4. Design Practice & 5. Creative Review & 4. Research Methods \\
4. Creative Experience & 4. Creative Experience & 5. Creative Review & 5. Research Operations \\
& 5. Post Verification & 6. Creative Experience & 7. Postive Experience & 6. Research Results \\
& & & & 7. Research Findings \\
\hline
\end{tabular}

(Source: this study.)

Each case is a variable, and its context or background is different. The purpose of the case study, in addition to sharing experience and passing on experience, is focused on presenting the creative ingenuity and logical thinking of the case to solve the problem through a complete discussion. If the creativity of individual case-solving problems can be repeated, someone will sort it into a certain "principle" and, then, after verification, the "knowledge" will be formed. The cognitive model of "research" can be seen in Figure 3.

\subsection{Methods}

According to the research purpose, the researcher designed the interview content (see Appendix A), and invited two scholars who established the OPOP model to answer, so as to understand their motives and goals. At the same time, the researchers also invited some students who used the OPOP model, and asked them to talk about their recognition of the OPOP model based on their actual experience, and what else they think the OPOP model has to improve (see Appendix B). 


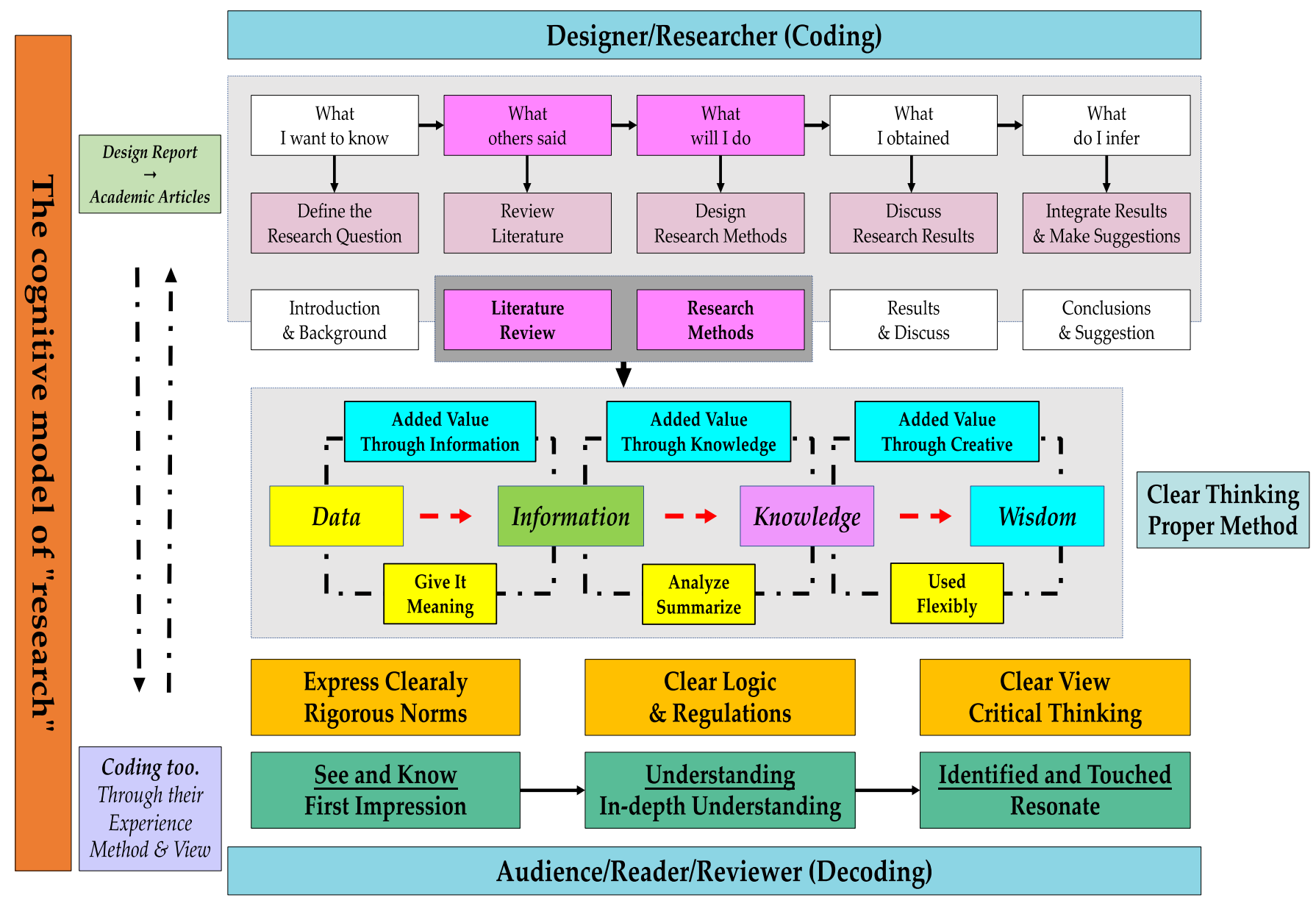

Figure 3. The cognitive model of "research". How to conduct research is an eternal topic. For students or researchers in the field of art and design, they prefer to create and write creation reports. In fact, even if it is a report on creation, how it lacks a scientific mode of thinking, it may not allow viewers to decode it correctly. From individual to general, this is exactly one of the goals that the OPOP model hopes to achieve. (Source: adapted from [33,34,42].)

Combining the opinions of experts and students, we further proposed future research ideas: we hope to continuously improve the OPOP model and extend it to more schools and departments (mainly in art, design, performance, and craft).

\section{Case Study for Applying and Validation OPOP Model \\ 4.1. The OPOP Model}

The categories of design and education are immense; unlike fine arts, design is a highly practical subject, and needs to pay more attention to the market's demand, not just as an ornament. The development and education models of most countries and regions are mostly influenced by Bauhaus. However, the OPOP model introduces research-oriented thinking into the creation. It allows students to explore the deeper meaning behind the creation while creating, and use a scientific method to further turn the creation into an article. In this way, not only can more people understand the connotation behind the creation, but also the long-term separation between theory and practice can be brought closer. Compared with the traditional design education curriculum system and mode, the concept of OPOP is relatively new, and we hope to make OPOP become a kind of "inertial thinking".

The OPOP model tries to provide students and researchers in the field of design and creativity with a way of thinking: let them look at practice with a research-based thinking, so we did not specify a particular field, which is why the first " $\mathrm{P}$ " can be continuously extended. It can be a product, a performance, a project, and a plan, etc. From the purpose of 
the establishment of the Graduate School of Creative Industry Design, the National Taiwan University of Arts (GSCID, NTUA) [46], we could clearly see the motivation and goal of the OPOP model-accumulating experience from "Cross-field Learning" to prepare for the future "Cross-border Service" (see Table 3). The author believes that, in the future, OPOP can be further promoted to the depth of "One Possibility, One Philosophy". Because the meaning of the second "P" in OPOP can be continuously extended, we believe that "One Possibility, One Philosophy" may be more representative at this stage. The OPOP model has been continuously improved and perfected, and we are confident to put forward new ideas in follow-up research.

Table 3. OPOP: From "Cross-field Learning" to "Cross-border Services".

\begin{tabular}{cccccc}
\hline \multicolumn{3}{c}{ Cross-Field Learning } & \multicolumn{3}{c}{ Cross-Border Services } \\
\hline One & Performance & $\rightarrow$ Creative & One & Ph. D & Position \\
One & Paper & One & Position & $\rightarrow$ Position \\
One & Project & $\rightarrow$ Industry & One & Position \\
One & Paper & One & Platform & $\rightarrow$ Platform \\
One & Product & $\rightarrow$ Design & One & Platform & $\rightarrow$ Progress \\
One & Paper & One & Progress & \\
\hline \multicolumn{5}{c}{ One Possibility, One Philosophy } \\
\hline \multicolumn{5}{c}{}
\end{tabular}

In order to fully understand the connotation of OPOP, this study interviewed two OPOP model founders (see Appendix A) and randomly selected a dozen students who used the OPOP model to fill out a questionnaire (see Appendix B). Due to space limitations, three cases were selected below to help readers understand how to apply the OPOP model to different studies. The author believes that the OPOP model has extremely broad scalability and good applicability.

In the next section, we shared three articles involving a plan, product, and project. These articles applied the essence of the OPOP model flexibly to research.

\subsection{Typical Cases}

The Ph.D. students recruited by GSCID had diverse backgrounds, such as design, architecture, crafts, painting, and performance, which were also in line with the motivation of GSCID and the goals of the cross-disciplinary research. Since September 2018, the OPOP model has become an important part of the GSCID series of courses. This section randomly selected three articles from the research articles that made extensive use of the OPOP model (see Appendix C) to further explain to readers how the OPOP model was used as a general model. These three articles based on the OPOP model passed the peer review and were officially published in the international seminar. These authors accepted questions from scholars from different countries or regions at the seminar. Generally speaking, although these articles still deserved to be improved, they showed that the OPOP model is reliable to a certain extent.

Our intention was to explain to more readers how the OPOP model was used in different fields. Due to space limitations, for the details of these articles, interested readers are welcome to further consult the full version of these articles (their titles are shown in Appendix C). At the same time, we look forward to your feedback to us after reading these articles. This is very helpful for us to further improve the OPOP model!

4.2.1. Case 1: Museum and Cultural Products Co-Creation Brand Value: Taking the Innovative Cultural Products of Ningbo Port Museum as an Example (One Plan, One Paper)

Chang [47] used the Ningbo Port Museum as a subject to discuss the issue of creating brand value between museums and cultural products. Chang pointed out that, to a degree, the 21st century is emotional, the new art exhibition trend will be accompanied by the viewer/consumer's experience, and the viewer/consumer's expectations for the future, 
consistent with the three connotations of culture, design, and marketing. Cultural products that conform to the museum's brand image could make the public more willing to return and pay attention to the pulse of the museum. Therefore, under the sharing and creation of the museum and its derivative cultural products, the museum can be endowed with brand value through a more attractive brand charm. In addition, museums that have a lot of room for development in creative industries can create more industries or service areas by enhancing brand value. In the article, the author constructed the museum cultural product brand derivation system (Figure 4), and the cultural innovation value-added design model from the cultural level to the design attributes (Figure 5), which provided a reference for research in related fields.

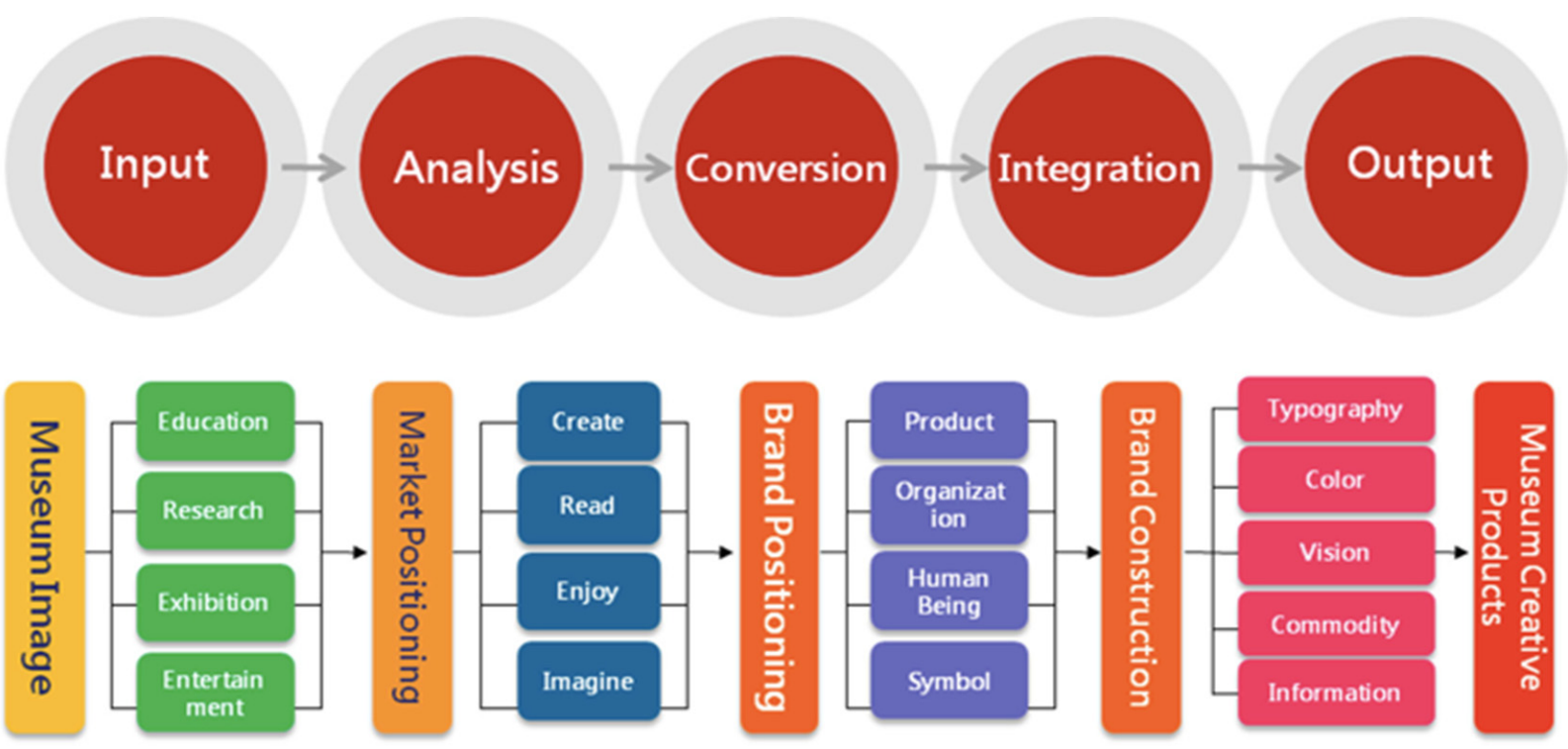

Figure 4. Museum cultural products brand derivative system. (Reprinted with permission from [47]. Copyright 2019 Chang.)

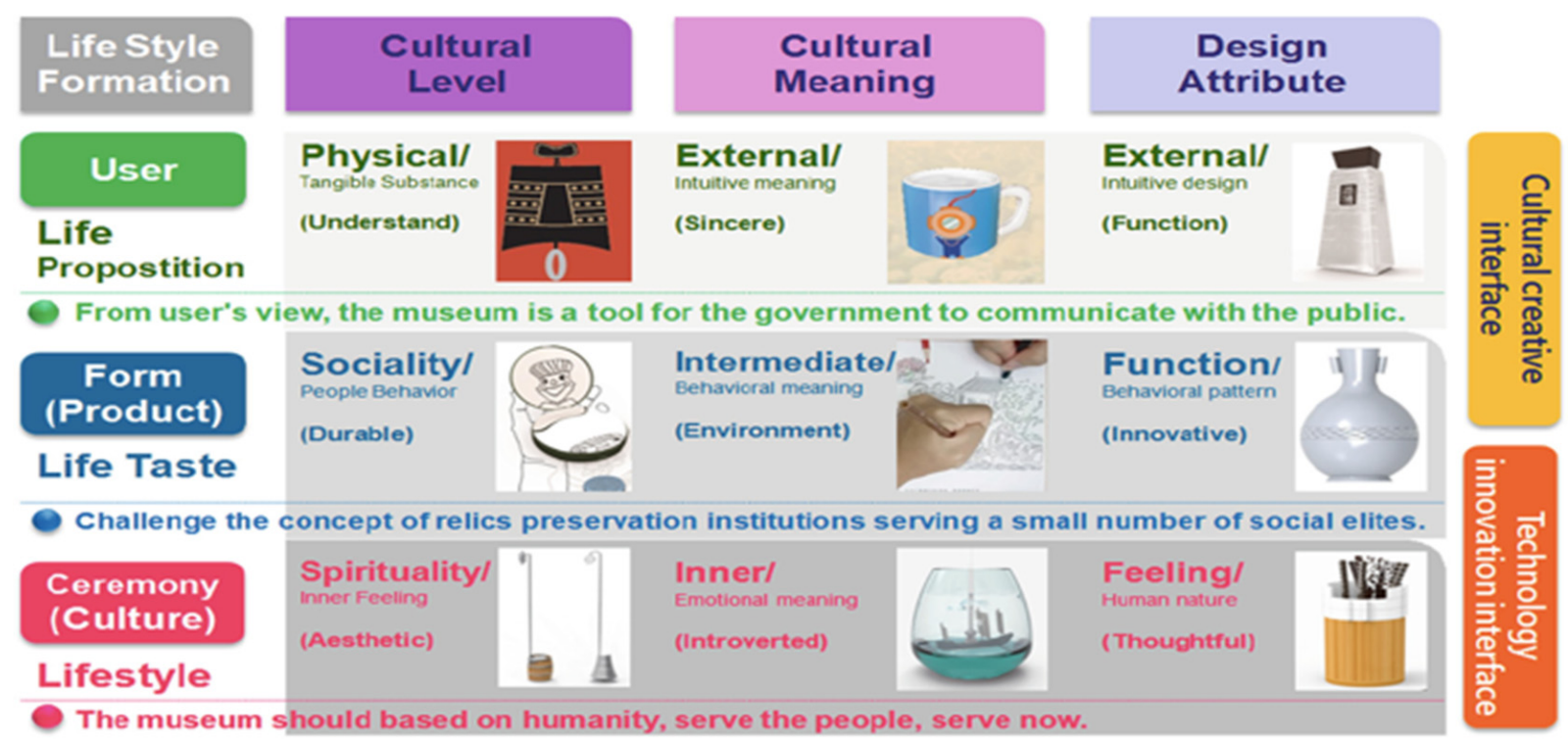

Figure 5. Cultural innovation value-added design model from the cultural level to design attribute. (Reprinted with permission from [47]. Copyright 2019 Chang.) 
4.2.2. Case 2: A Study of Cultural Ergonomics in Atayal Weaving Box (One Product, One Paper)

How to combine traditional culture with modern design and construct a design model of cultural products has become a hot topic in recent years. Based on the previous studies, many scholars have conducted a series of related studies on this issue [48,49]. Kreifeld et al. [48] proposed a cultural ergonomic research model to provide designers with a valuable reference for designing a successful cross-cultural product as well as the interwoven experience of design and culture in the design process. They attempted to illustrate how, by enhancing the original meaning and images of Taiwan's aboriginal culture features, they may be transformed into modern products by taking advantage of new production technology, and so, fulfill the needs of the contemporary consumer market. They proposed a cultural ergonomic research model to provide designers with a valuable reference for designing a successful cross-cultural product as shown in Figure 6 [49].

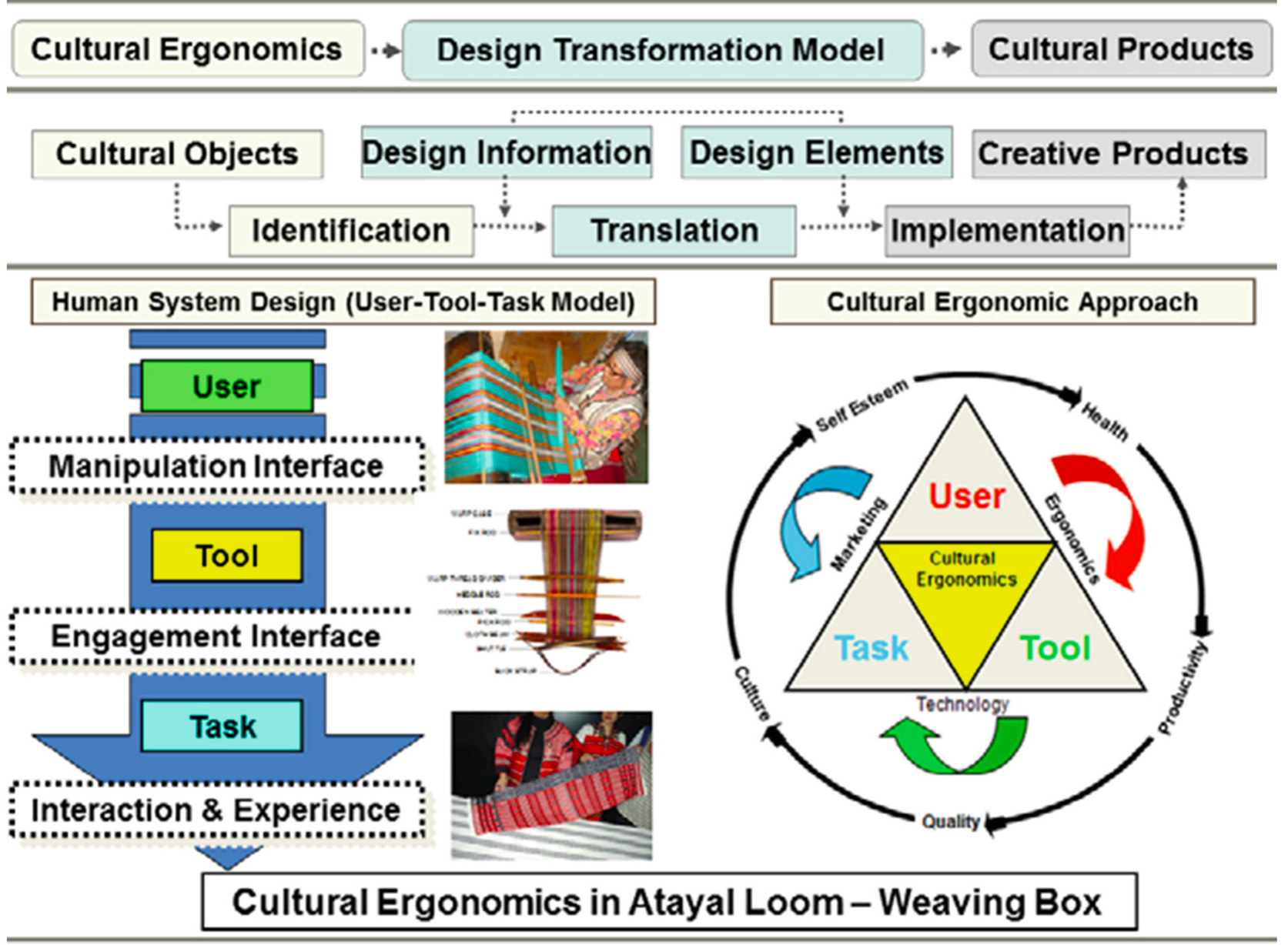

Figure 6. A cultural ergonomic research model in Atayal loom. (Reprinted with permission from [49]. Copyright 2016 Taru et al.)

4.2.3. Case 3: A Study of Japan's Welfare Beauty Service from Cultural Creative's Perspective (One Project, One Paper)

The concept of "service design" focuses on enterprise service planning and management. It also emphasizes systematic methods and customer-centric thinking. The population ageing problem has also attracted the attention of scholars in the field of design and creativity. Lin, Yen and Chen [50] shifted their focus from designing a specific product and planning a specific project to the current and important topic of population aging. At the same time, they found another way to explore the characteristics and advantages of Japanese welfare and beauty services from the perspective of cultural creativity. From 
Figure 7 , it is not difficult to see that they grasped the OPOP model and reorganized the relevant research structure according to specific research objects.

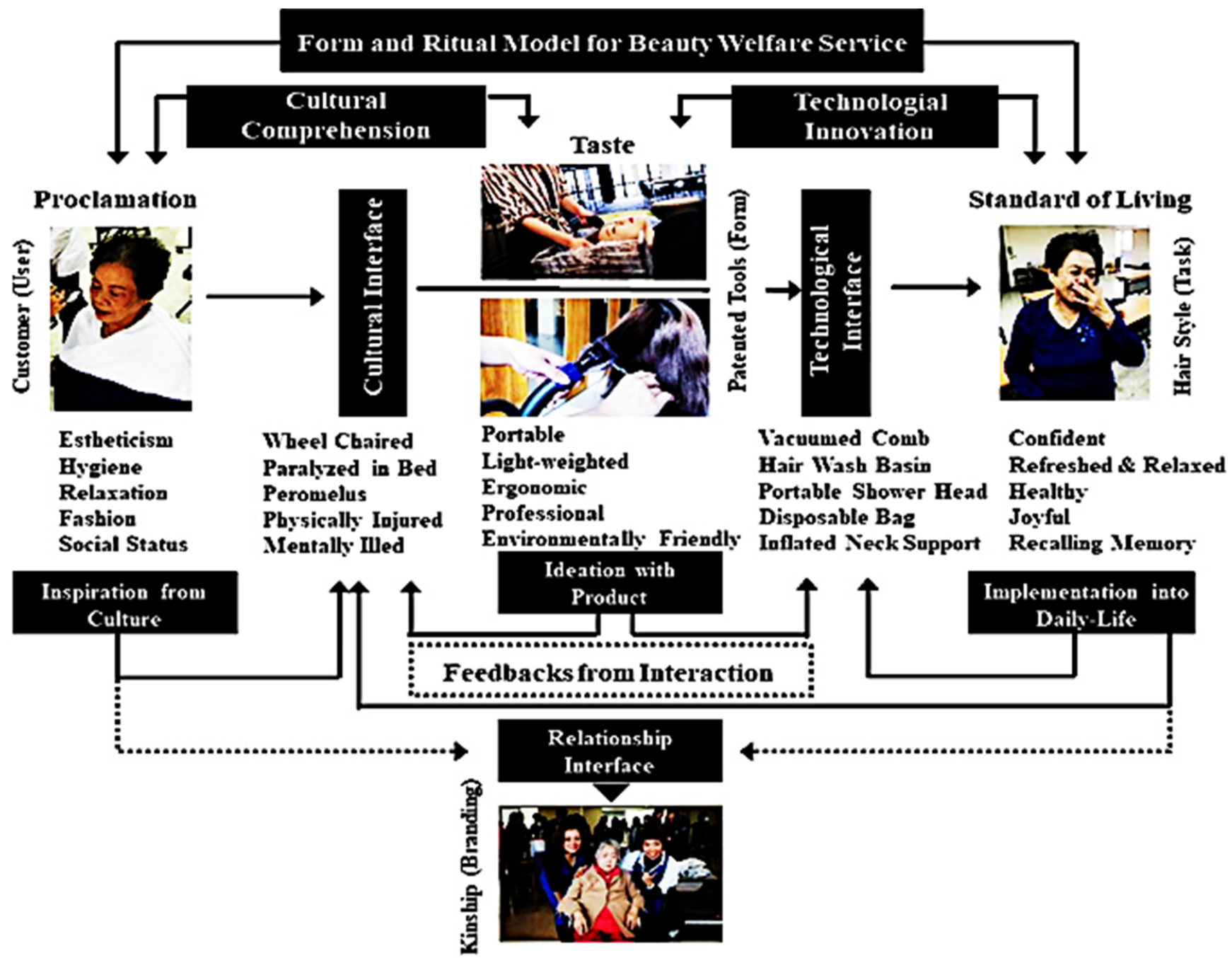

Figure 7. Form and ritual design model for cultural innovation. (Reprinted with permission from [50]. Copy 2019 Lin, C. et al.)

\subsection{Participants' Response and Suggestions}

Any model and method accumulates experience in practice, improving its details and structure. Although the core theory of the OPOP model is relatively mature, as a relatively new teaching model it still deserves further improvement. The author invited a dozen students who participated in the OPOP forum to conduct research (see Appendix B). They were mainly from GSCID, NTUA. Due to the limited number of participants, the following survey results are for reference only:

- Except for one student who had been exposed to a model similar to OPOP before, the other students, such as the author, were all exposed to the OPOP model for the first time. Everyone gave good comments on the OPOP model. They thought they could obtain a lot of inspiration from it and integrated such research methods into subsequent creation and research; they were also willing to introduce and share the OPOP model with others.

- Many participants believe that it is necessary to further promote the OPOP model by such means as strengthening exchanges with other colleges and departments, holding OPOP forums in other schools, and extending this model to the teaching of universities and master's classes. In addition, several students mentioned that they hoped to make 
the conversion process of "From Product to Paper" more concrete and, at the same time, increase the part of "post verification".

\section{Conclusions}

Since 2018, the OPOP model has become an integral part of the GSCID's curriculum system. Up to now, more than 30 doctoral and master's students have carried out various researches based on the concept of the OPOP model. Therefore, we believe that the OPOP model is relatively successful and feasible. On the one hand, its core theory has been verified many times and a series of structures and systems have been formed which could be flexibly adjusted according to different research topics. On the other hand, OPOP itself is an open model which allows us freedom in the process of applying it.

For readers who were exposed to OPOP for the first time, it is recommended to randomly select 1-2 articles from Appendix $C$ for reading. At the same time, you can ask yourself, if you were to conduct the same type of research, would you also take a similar approach? In other words, could you obtain inspiration from the OPOP model? This was also the learning method the author took when he first came into contact with the OPOP model. It should be pointed out that there are many research methods and models in any professional field. Therefore, the author hopes that readers can use "critical thinking" to examine the OPOP model.

Regarding the future development of the OPOP model, as the participants stated, it is necessary to expand contacts, such as with teachers and students from other schools, and even professional designers, so that more people can understand, use, and think about the OPOP model. Although the articles participating in the OPOP forum were all officially published in different symposiums or journals, the author believes that under the premise of not violating academic ethics, these articles can be considered as a collection of essays and provided to interested readers.

We hope to construct a "general rule" through the OPOP model, but leave as much space as possible for researchers to develop themselves. The motivation of the OPOP model and the research process are based on the accumulation of "individual" one by one, and gradually move towards "general". It is true that any model needs to be continuously improved in the process. Therefore, we will extend this model to different departments and schools (focusing on the fields of art, design, performance, crafts, etc.), and continue to verify this model through feedback from students and scholars.

Author Contributions: Data curation, R.L.; Project administration, R.L.; Resources, P.-H.L.; Writingoriginal draft, Y.S. All authors have read and agreed to the published version of the manuscript.

Funding: This research was funded by The Start-up Fund for the Research of "Metasequoia Teachers" of Nanjing Forestry University, China, grant number 163103077".

Institutional Review Board Statement: Not applicable.

Informed Consent Statement: Informed consent was obtained from all subjects involved in the study.

Data Availability Statement: Data sharing not applicable.

Conflicts of Interest: The authors declare no conflict of interest.

\section{Appendix A}

The author also invited the founders of the OPOP model and asked them to answer four questions in the form of an interview. They participated in all three forums throughout the process, and they were also the instructors of all articles published in the forums. The four subjective questions in the interview are shown in Table A1. 
Table A1. The content of the interview.

Dear Instructor:

Introduction

The OPOP Forum has been successfully held three times, and it has become a challenge faced by GSCID freshmen after enrollment. To a certain extent, it allows freshmen to quickly enter the research state after enrollment. More importantly, this forum is a platform for everyone to exchange and learn from each other. The author once had the honor to participate in a forum named OPOP. It was also the first time the author came into contact with the OPOP model and learned a lot from it. I am currently writing a paper discussing the application of the OPOP model in design and creative teaching, hoping to comprehensively and objectively evaluate and think about the OPOP model, and share this model with more people.

As the creator, organizer, and instructor of the OPOP model, your motivation for creating OPOP and your experience in the process of guiding students will be an important reference for the author when studying the ins and outs and connotation of the OPOP model.

It would be a great favor if you would spend $10 \mathrm{~min}$ to answer this interview. The answers will be used solely for academic purposes and individual information will be kept strictly confidential.

Thank you for your generous participation and cooperation!

Sincerely,

Yikang Sun

17 April 2021

\section{Questions}

1. What was your motivation and rationale for constructing the OPOP model?

2. What do you think is the difference between the OPOP model and other teaching and research models in the field of design and creativity? What are the advantages of the OPOP model?

3. Based on the results of the three forums that were held, what do you think we should pay attention to when we use the OPOP model?

4. Based on the results of the three forums that were held, what do you think can be adjusted for the OPOP model?

\section{Appendix B}

The author invited a dozen students who participated in OPOP forums, and asked them to answer related questions in the form of questionnaires. These students come from the Graduate School of Creative Industry Design, National Taiwan University of Arts (GSCID, NTUA). The content of the questionnaire is shown in Table A2.

Table A2. The content of the questionnaire.

\section{Dear friends of GSCID, NTUA:}

\section{Introduction}

The OPOP forum is a big event of GSCID, NTUA. It is a platform for everyone to learn from each other, and it is our common memory! The author is writing a paper related to the OPOP model. The author hopes to evaluate and think about the OPOP model in a more comprehensive and objective manner, and to share this model with more people to participate in the grand event.

It would be a great favor if you would spend $10 \mathrm{~min}$ to answer this questionnaire. The answers will be used solely for academic purposes and individual information will be kept strictly confidential.

Thank you for your generous participation and cooperation!

\section{Basic Information}

\section{Gender}

$$
\square \text { Male } \quad \square \text { Female }
$$

2. Background

$\square$ Art $\quad \square$ Design $\quad \square$ Architecture $\quad \square$ Crafts $\quad \square$ Pedagogic $\quad \square$ Performance $\square$ Other

3. How many times have you participated in an OPOP forum?

$\square 1 \quad \square 2 \quad \square 3$


Table A2. Cont.

\section{Questions}

1. Have you been exposed to the same or similar models as OPOP in the past?

$\square$ Yes (identical) $\quad \square$ Yes (analogous) $\quad \square$ No

2. Do you think you can adjust to the OPOP model?

$\square$ Yes $\quad \square$ No $\quad \square$ Uncertain

3. Can the OPOP model inspire you?

$\square$ Yes $\quad \square$ No $\quad \square$ Uncertain

4. Are you in agreement with the OPOP model?

$\square$ Yes $\quad \square$ No $\quad \square$ Uncertain

5. Will you apply what you have learned in the OPOP model to your everyday creative and research activities?

$\square$ Yes $\quad \square$ No $\quad \square$ Uncertain

6. Will you introduce the OPOP model to others?

$\square$ Yes $\quad \square$ No $\quad \square$ Uncertain

7. Do you think there are other parts of the OPOP model that are worth adjusting or improving?

\section{Appendix C}

Since 2018, the OPOP forum has been successfully held three times, and the 4th forum is expected to be held in the second half of 2021. The articles used in the first three forums are shown in Table A3. The content of these articles already surpassed design in the traditional sense, covering a wide range, including product design, visual design, craft design, ceramic design, interior design, painting, clothing, interaction, installation art, social welfare, etc. This greatly extends the connotation of the first " $\mathrm{P}$ ". These articles were further revised and improved, and most of them were accepted by international seminars such as the Human-Computer Interaction International Conference (HCI), or published in journals.

Table A3. List of articles used in OPOP forum, 2018-2020.

\begin{tabular}{|c|c|}
\hline Title of Articles & Author(s) \\
\hline $\begin{array}{l}\text { Research on the audience's cognition and preference } \\
\text { of the styles of Chinese landscape paintings }\end{array}$ & Wu, J.; Wu, J.D.; Lin, P.H. \\
\hline $\begin{array}{l}\text { Research on the application of innovation and } \\
\text { inheritance based on regional culture: A case study } \\
\text { of the innovative design of Atayal knitting box } \\
\text { in Taiwan }\end{array}$ & Gao, Y.J. \\
\hline $\begin{array}{l}\text { A study model on the transformation of "artwork" } \\
\text { to "interior design": Take the series of "poetic } \\
\text { artwork" series as an example }\end{array}$ & Gao, Y.J. \\
\hline $\begin{array}{l}\text { Research on the influence of interactivity on the } \\
\text { aesthetic cognition of art }\end{array}$ & Gao, Y.; Wang, I.T.; Lin, P.H.; Lin, R. \\
\hline Designing gardenia-inspired cultural products & Kuo, S.L. \\
\hline $\begin{array}{l}\text { Assessment of the sense of joy in public artwork in } \\
\text { living environment }\end{array}$ & Lo, H.F. \\
\hline $\begin{array}{l}\text { Analysis of cover design styles of magazines: } \\
\text { Taking The Short Story Magazine (1910-1932) as } \\
\text { an example }\end{array}$ & Huang, J.P.; Chen, S.; Wu, J.D.; Lin, R. \\
\hline $\begin{array}{l}\text { A case study of applying 'Black Humor' to ceramic } \\
\text { art performance }\end{array}$ & Hsu, M.L.; Fang, W.T.; Lin, P.H.; Lin, R. \\
\hline A dialed between nature and man-made and beyond & Wang, I.T.; Lo, H.F.; Gao, Y. \\
\hline
\end{tabular}


Table A3. Cont.

\begin{tabular}{|c|c|}
\hline Title of Articles & Author(s) \\
\hline $\begin{array}{l}\text { Study on the aesthetic characteristics of Chinese } \\
\text { Chan tea: Cultural elementsand innovative } \\
\text { thinking of tea and Chan }\end{array}$ & Wen, $X$. \\
\hline $\begin{array}{l}\text { Research on the marketing strategy of green design } \\
\text { products: Taking "AURO" and "Even" brand } \\
\text { products as examples }\end{array}$ & Wen, W.I. \\
\hline Research on creation architecture of opera cartoons & Wu, J.D.; Huang, J.P.; Lin, R. \\
\hline $\begin{array}{l}\text { Comparative analysis of the transition process from } \\
\text { painting and calligraphy to ceramics }\end{array}$ & Yang, C.H. \\
\hline $\begin{array}{l}\text { Museum and cultural products co-creation brand } \\
\text { value: Taking the innovative cultural products of } \\
\text { Ningbo Port Museum as an example }\end{array}$ & Chang, C.W. \\
\hline $\begin{array}{l}\text { A feasibility study on the transformation and } \\
\text { sustainable development of "Disposable Tableware" } \\
\text { in Taiwan night market }\end{array}$ & Sun, Y.; Lin. S.Y. \\
\hline $\begin{array}{l}\text { A study of Japan's beauty welfare service from } \\
\text { cultural innovative perspective }\end{array}$ & Lin, C.L.; Chen, C.L. \\
\hline $\begin{array}{l}\text { Traditional board game revitalization: A Case study } \\
\text { of Bas-basan Sepur }\end{array}$ & Armayuda, E. \\
\hline $\begin{array}{l}\text { A study on application of enclothed cognition in } \\
\text { apparel design }\end{array}$ & Lin, S.Y. \\
\hline The pilot study of the theater of the Bauhaus & Ting, Y.W. \\
\hline $\begin{array}{l}\text { Visual data storytelling: A case study of turning } \\
\text { big data into Chinese painting }\end{array}$ & Lyu, Y.R. \\
\hline $\begin{array}{l}\text { Research on the utilization of unconventional } \\
\text { materials in fashion styling }\end{array}$ & Cheng, T.F. \\
\hline $\begin{array}{l}\text { Museum immersion interactive design: Taking the } \\
\text { children art gallery exhibition as an example }\end{array}$ & Chang, C.W. \\
\hline $\begin{array}{l}\text { Application of auspicious cultural in metalworking } \\
\text { jewelry design }\end{array}$ & Shi, M.H. \\
\hline $\begin{array}{l}\text { Research on the application of family elements in } \\
\text { environmental education exhibition }\end{array}$ & Yang, C.H. \\
\hline $\begin{array}{l}\text { A case study of applying 'Black Humor' to ceramic } \\
\text { art performance }\end{array}$ & Hsu, M.L. \\
\hline $\begin{array}{l}\text { A study of applying Bauhaus design idea into the } \\
\text { reproduction of the Triadic Ballet }\end{array}$ & Ting, Y.W. \\
\hline $\begin{array}{l}\text { The co-creation of value between product } \\
\text { development and customer experience: Taking } \\
\text { "Silkah" as an example }\end{array}$ & Huang, M.L. \\
\hline $\begin{array}{l}\text { Discussing how the viewer, the author, and the } \\
\text { work see and be seen in the photography works of } \\
\text { Farewell to the Island }\end{array}$ & Cheng, H.C. \\
\hline $\begin{array}{l}\text { Transforming the local cultural resources into } \\
\text { design: A case study of the Hengshan } \\
\text { region placemaking }\end{array}$ & Chiang, I.Y. \\
\hline $\begin{array}{l}\text { Exploring the integration of emotion and } \\
\text { technology to create product value: using } \\
\text { QisDesign lighting as example }\end{array}$ & Chen, J.F. \\
\hline $\begin{array}{l}\text { The unorthodox use of bamboo in fashion } \\
\text { styling design }\end{array}$ & Cheng, T.F. \\
\hline
\end{tabular}


Table A3. Cont.

\begin{tabular}{|c|c|}
\hline Title of Articles & Author(s) \\
\hline $\begin{array}{l}\text { Sightseeing illustration map design and } \\
\text { effectiveness research: A case study of Hong Kong } \\
\text { sightseeing illustration map }\end{array}$ & Wu, H.C. \\
\hline $\begin{array}{l}\text { Redesign, transformation and reflection of local } \\
\text { marriage custom articles: A case study of "the } \\
\text { Red Dowry" }\end{array}$ & Cao, J. \\
\hline $\begin{array}{l}\text { Audience's cognitive research on "incomplete" } \\
\text { technique in sculpture art }\end{array}$ & Tao, Y.H. \\
\hline Discussion on Zen mind design of products & Huang, T.F. \\
\hline $\begin{array}{l}\text { The interweaving of memory and recollection: A } \\
\text { case study of memorial house "Qiyun Residence" }\end{array}$ & Sun, Y.; Lin, R. \\
\hline
\end{tabular}

\section{References}

1. Archer, L.B. What is good design. Design Awareness and Creativity in Industry; Design Council: London, UK, 1974; pp. 17-38.

2. Bentley, D. The Greatest Designs of Modern Times. Available online: https://fortune.com/longform/100-best-designs / (accessed on 16 March 2020).

3. Doblin, J. One Hundred Great Product Designs; Van Nostrand Reinhold: New York, NY, USA, 1970.

4. Jong, C.; Klemp, K.; Mattie, E.; Rams, D. Ten Principles for Good Design; Prestel: Munich, Germany, 2017.

5. Norman, D.A. The Design of Everyday Things; Basic Books: New York, NY, USA, 2013.

6. Rams, D. Omit the unimportant. Desi. Issues 1984, 1, 24-26. [CrossRef]

7. Rams, D. Less and More: The Design Ethos of Dieter Rams; Die Gestalten Verlag: Berlin, Germany, 2011.

8. $\quad$ Rams, D. Less But Better; Die Gestalten Verlag: Berlin, Germany, 2014.

9. Orr, C. Philippe Starck's Juicy Salif Lemon Squeezer: Genius Design or Just a Cool Fruit Squeezer? Available online: https: / / medium.com/designstudies1/philippe-starcks-juicy-salif-lemon-squeezer-genius-design-or-just-a-cool-fruitsqueezer-d2b41634407c (accessed on 26 April 2019).

10. Norman, D.A. Emotional Design: Why We Love (or Hate) Everyday Things; Basic Books: New York, NY, USA, 2005.

11. Bredendieck, H. The legacy of the Bauhaus. Art J. 1962, 22, 15-21. [CrossRef]

12. Findeli, A. Moholy-Nagy's design pedagogy in Chicago (1937-46). Des. Issues 1990, 7, 4-19. [CrossRef]

13. Harrington, K. Bauhaus symposium. Des. Issues 1988, 5, 45-58. [CrossRef]

14. Lerner, F. Foundations for design education: Continuing the Bauhaus vorkurs vision. Stud. Art Educ. 2005, 46, 211-226. [CrossRef]

15. Phelan, A. The Bauhaus and studio art education. Art Educ. 1981, 34, 6-13. [CrossRef]

16. Raleigh, H.P. Johannes Itten and the background of modern art education. Art J. 1968, 27, 284-302. [CrossRef]

17. Amagai, Y. The Kobu Bijutsu Gakko and the beginning of design education in modern Japan. Des. Issues 2003, 19, 35-44. [CrossRef]

18. Hirano, T. The development of modern Japanese design: A personal account. Des. Issues 1991, 7, 54-62. [CrossRef]

19. Kikuchi, Y.; Lee, Y. Transnational modern design histories in East Asia: An introduction. J. Des. Hist. 2014, 27, 323-334. [CrossRef]

20. Kikuchi, Y. Design histories and design studies in East Asia: Part 1. J. Des. Hist. 2011, 24, 273-282. [CrossRef]

21. Lee, Y. Design histories and design studies in East Asia: Part 3 Korea and conclusion. J. Des. Hist. 2012, 25, 93-106. [CrossRef]

22. Lin, C.L.; Huang, J.P.; Lin, R. From STEAM to CHEER: A case study of design education development in Taiwan. Educ. Sci. 2021, 11, 171. [CrossRef]

23. Lu, C.C.; Lin, R. The influence of Bauhaus style on Taiwan design education. Art Appreciation 2010, 6, $28-43$.

24. Wong, W.S. Design history and study in East Asia: Part 2 greater China: People's Republic of China/Hong Kong/Taiwan. J. Des. Hist. 2011, 24, 375-395. [CrossRef]

25. Wu, M.C.; Chang, W.L.; Chen, C.C. Retrospect and prospect of design education in Taiwan. Taiwan Educ. Rev. 2012, 674, 77-80.

26. Chien, C.W.; Lin, C.L.; Lin, R. A study of five " $\mathrm{F}$ " in product design. In Bridging Research and Good Practices towards Patients Welfare: Proceedings of the 4th International Conference on Healthcare Ergonomics and Patient Safety (HEPS); Shih, Y.C., Liang, S.F.M., Eds.; CRC Press: Boca Raton, FL, USA, 2014; p. 409.

27. Hsu, C.H.; Chang, S.H.; Lin, R. A design strategy for turning local culture into global market products. Int. J. Affect. Eng. 2013, 12, 275-283. [CrossRef]

28. Hsu, C.H.; Fan, C.H.; Lin, J.Y.; Lin, R. An investigation on consumer cognition of cultural design products. Bull. Jpn. Soc. Sci. Des. 2014, 60, 39-48. [CrossRef]

29. Bequette, J.W.; Bequette, M.B. A place for art and design education in the STEM conversation. Art Educ. 2012, 65, 40-47. [CrossRef]

30. Findeli, A. Design history and design studies: Methodological, epistemological and pedagogical inquiry. Des. Issues 1995, 11, 43-65. [CrossRef] 
31. Findeli, A. Rethinking design education for the 21st century: Theoretical, methodological, and ethical discussion. Des. Issues 2001, 17, 5-17. [CrossRef]

32. Hanington, B.M. Relevant and rigorous: Human-centered research and design education. Des. Issues 2010, 26, 18-26. [CrossRef]

33. Norman, D.A. Design Education: Brilliance Without Substance. Available online: https://www.core77.com/posts/20364/ Design-Education-Brilliance-Without-Substance (accessed on 4 October 2011).

34. Norman, D.A. Why Design Education Must Change. Available online: https://www.core77.com/posts/17993/why-designeducation-must-change-17993 (accessed on 26 November 2016).

35. Norman, D.A. State of Design: How Design Education Must Change. Available online: https://jnd.org/this_post_is_part_of/ (accessed on 3 December 2018).

36. Lin, R.; Kreifeldt, J.; Hung, P.H.; Chen, J.L. From Dechnology to Humart—A case study of Taiwan design development. In Proceedings of the 7th International Conference, CCD 2015, Cross-Cultural Design Applications in Mobile Interaction, Education, Health, Los Angeles, CA, USA, 2-7 August 2015; Held as Part of HCI International 2015. Springer: Cham, Switzerland; pp. $263-273$.

37. Lin, R. Looking at Taiwan's future design development from Young Designers' Exhibition (YODEX) (Part I). Available online: https: / / www.brain.com.tw/news/articlecontent?ID=18741 (accessed on 18 September 2021).

38. Lin, R. Looking at Taiwan's future design development from Young Designers' Exhibition (YODEX) (Part II). Available online: https: / / www.brain.com.tw / news/articlecontent?ID=18746 (accessed on 18 September 2021).

39. Lin, R. The Influence of Bauhaus Style on Taiwan Design Education. In Proceedings of the International Symposium to Commemorate the 90th Anniversary of the Bauhaus; Fu Jen Catholic University: New Taipei, Taiwan, 2009; pp. 59-76.

40. Lawrie, E. Could a Computer Ever Create Better Art Than A Human? Available online: https://www.bbc.com/news/business47700701 (accessed on 23 April 2019).

41. Hansman, R.J.; Silbey, R.J. Report of the Presidential Task Force Student Life and Learning. Available online: http:/ web.mit. edu/evolving/message.html (accessed on 6 December 2011).

42. Lin, R.; Lin, P.H.; Lu, C.C.; Sun, M.X. Discussion on the curriculum planning concept of creative industry design institute. In Proceedings of the Retrospect and Prospect of Bauhaus for 90 Years, 2009 The Design Seminar of Craft \& Design, New Taipei, Taiwan, 23 October 2009; National Taiwan University of Arts: New Taipei, Taiwan; pp. 4-29.

43. Ackoff, R.L. From data to wisdom. J. Appl. Syst. Anal. 1989, 16, 3-9.

44. Baskarada, S.; Koronios, A. Data, information, knowledge, wisdom (DIKW): A semiotic theoretical and empirical exploration of the hierarchy and its quality dimension. Australas. J. Inf. Syst. 2013, 18, 5-24. [CrossRef]

45. Rowley, J. The wisdom hierarchy: Representations of the DIKW hierarchy. J. Inf. Sci. 2007, 33, 163-180. [CrossRef]

46. Graduate School of Creative Industry Design (GSCID). The Purpose of the Establishment of the Institute. Available online: https:/ / cid.ntua.edu.tw/gscid-en/index.html\#introduction (accessed on 17 April 2021).

47. Chang, C.W. Museum and cultural products co-creation brand value: Taking the innovative cultural products of Ningbo Port Museum as an example. In Proceedings of the 11st International Conference, CCD 2019, Held as Part of HCI International 2019, Orlando, FL, USA, 26-31 July 2019; Held as Part of HCI International 2019; Springer: Cham, Switzerland; pp. 17-32. [CrossRef]

48. Kreifeld, J.; Gao, Y.; Yang, G.; Yen, H.; Taru, Y.; Lin, R. A study of cultural ergonomics in Atayal weaving box. In Proceedings of the 11st International Conference, CCD 2019, Held as Part of HCI International 2019, Orlando, FL, USA, 26-31 July 2019; Held as Part of HCI International 2019; Springer: Cham, Switzerland; pp. 170-183. [CrossRef]

49. Taru, Y.; Kreifeldt, J.; Sun, M.; Lin, R. Thoughts on studying cultural ergonomics for the Atayal loom. In Proceedings of the 8th International Conference, CCD 2016, Held as Part of HCI International 2016, Toronto, ON, Canada, 17-22 July 2016; Held as Part of HCI International 2016; Springer: Cham, Switzerland; pp. 377-388. [CrossRef]

50. Lin, C.L.; Yen, H.Y.; Chen, C.L. A study of Japan's welfare beauty service from cultural creative's perspective. In Proceedings of the 11st International Conference, CCD 2019, Held as Part of HCI International 2019, Orlando, FL, USA, 26-31 July 2019; Held as Part of HCI International 2019; Springer: Cham, Switzerland; pp. 309-324. [CrossRef] 